\title{
Bismuth induced encephalopathy caused by tri potassium dicitrato bismuthate in a patient with chronic renal failure
}

\author{
R J Playford, C H Matthews, M J Campbell, H T Delves, K K Hla, H J F Hodgson, J Calam
}

Department of Medicine, Royal Postgraduate Medical School,

Hammersmith Hospital, London

R J Playford

C.H Matthews

H J F Hodgson

J Calam

\section{Trace Element Unit} Department of Clinical Biochemistry,

Southampton General

Hospital, Southampton

M J Campbell

H T Delves

Poisons Unit, New Cross Hospital, London

K K Hla

Correspondence to: $\mathrm{R} \mathrm{J}$ Playford, MRC Training Fellow, Gastroenterology Unit, Royal Postgraduate Medical School

Hammersmith Hospital, Du Cane R

Accepted for publication 10 May 1989 Hammersmith Hospital

\begin{abstract}
A 68 year old man with a creatinine clearance rate of only $15 \mathrm{ml} / \mathrm{min}$ took twice the recommended dose of tripotassium dicitrato bismuthate (TDB) as DeNol ${ }^{\mathrm{TM}}$ liquid; $10 \mathrm{ml}$ qds; a total of $864 \mathrm{mg}$ bismuth daily for two months. Whole blood bismuth concentrations rose to $880 \mu \mathrm{g} / \mathrm{l}$ and he developed global cerebral dysfunction with hallucinations, ataxia, and an abnormal EEG. Renal clearance of bismuth rose from 0.24 to $2.4 \mathrm{ml} / \mathrm{min}$ when the heavy metal chelator 2-3 dimercapto-1 propane sulphonic acid (DMPS) was given by mouth. Bismuth was measured by a novel method involving inductively coupled plasma source mass spectrometry. Fifty days after stopping TDB, whole blood bismuth concentrations fell to $46 \mu \mathrm{g} / 1$ and the patient's EEG returned to normal. His mental function also recovered completely. The case serves as a timely reminder that TDB should not be administered to patients with renal disorders, as stated in the data sheet.
\end{abstract}

\section{Case report}

A 68 year old man presented with progressive confusion and difficulty walking over two weeks. He had a history of splenectomy for hereditary

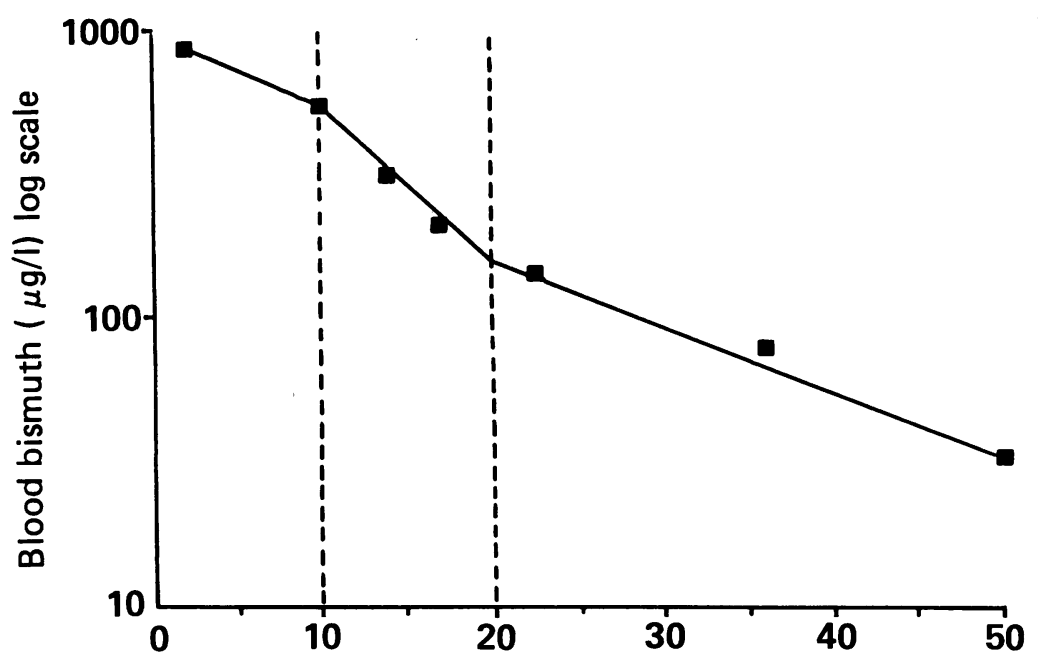

Time after stopping TDB (days)

Whole blood bismuth concentrations during the patient's admission. Tri-potassium dicitrato bismuthate $(T D B)$ was discontinued on day 0 . The dashed lines indicate the beginning and end of treatment with the chelator 2-3 dimercapto-1-propane sulphonic acid (DMPS). spherocytosis, maturity onset diabetes, hypertension, ischaemic heart disease and chronic renal impairment with a creatinine clearance rate of $15 \mathrm{ml} / \mathrm{min}$ for the past two years. For 10 years he had suffered repeated upper gastrointestinal bleeding. This had continued despite subtotal gastrectomy the year before. Before admission, gastritis was diagnosed and sucralfate; $1 \mathrm{~g}$ qds and TDB as DeNol ${ }^{\mathrm{TM}}$ liquid; $5 \mathrm{ml}$ qds prescribed. The patient actually took sucralfate $1 \mathrm{~g}$ qds, but $10 \mathrm{ml} \mathrm{DeNol}^{\mathrm{TM}}$ qds. He therefore ingested $864 \mathrm{mg}$ bismuth per day which is twice the recommended dose. He had continued this dose for an uninterrupted period of two months. At the same time he was taking frusemide, enalapril, glibenclamide, ferrous sulphate, and vitamin $B_{12}$.

On examination he was alert, but there was evidence of global cerebral dysfunction, including disinhibited behaviour, urinary incontinence, bilateral grasp reflexes, visual hallucinations, and ataxia. There were no focal neurological signs, however, and no other abnormal physical findings.

There was no evidence of gastrointestinal bleeding, infection, or myocardial infarction, and no change in his diabetic control or renal or hepatic function to account for the change in his cerebral function. A cranial computed tomography scan showed no focal lesion, but an EEG showed loss of alpha rhythm and diffuse slow waves consistent with a metabolic encephalopathy. Serum calcium, aluminium, magnesium, $B_{12}$, and folate concentrations were all normal. The plasma urea concentration was $15.8 \mathrm{mmol} / \mathrm{l}$ (normal range $2 \cdot 5-7 \cdot 5 \mathrm{mmol} / \mathrm{l}$ ), and the plasma creatinine concentration was $179 \mu \mathrm{mol} / \mathrm{l}$ (normally 50-110 $\mu \mathrm{mol} / \mathrm{l}$ ) in keeping with his chronic renal impairment. A clinical diagnosis of bismuth-induced encephalopathy was made and treatment with TDB was discontinued. The whole blood bismuth concentration was subsequently found to be $880 \mu \mathrm{g} / \mathrm{l}$. Urinary concentration at the same time was $230 \mu \mathrm{g} / \mathrm{l}$. The patient was then given $100 \mathrm{mg}$ tds of the heavy metal chelator 2-3 dimercapto-1propane sulphonic acid (DMPS) by mouth for 10 days. Renal clearance of bismuth increased from $0.24 \mathrm{ml} / \mathrm{min}$ before introduction of DMPS to 2.4 $\mathrm{ml} / \mathrm{min}$ during treatment with the chelator. Over the next 50 days whole blood bismuth concentrations fell (Figure) and there was a marked improvement in his cerebral function. The 
patient's EEG was normal six weeks after admission. He was discharged home seven weeks after admission and remains well four months later. All the signs of cerebral dysfunction described above disappeared.

\section{BISMUTH ESTIMATION}

Bismuth concentrations were measured by the method of inductively coupled plasma source spectrometry (ICP-MS). This is a new, extremely sensitive analytical technique in which sample solutions are nebulised into a high temperature $(10000 \mathrm{~K})$ argon plasma to produce analyte ions which are extracted into a quadrupole mass spectrometer for separation and measurement. Almost all elements of clinical and biochemical significance can be measured at picomolar and nanomolar concentrations using only $100-200 \mu \mathrm{l}$ volumes of blood, serum, or urine. 'The accuracy and precision of the data are within $\pm 3 \%$ of the reported values.

\section{Discussion}

Bismuth induced encephalopathy was first described in 1973, in an Australian who took bismuth subgallate as an ileostomy deodorant. ${ }^{2}$ Nearly a thousand cases occurred in France over the next five years in patients taking various bismuth salts. ${ }^{3}$ This led to the withdrawal of bismuth salts from several countries. Victims had usually taken high doses for long periods; typically $1.5-20 \mathrm{~g}$ bismuth per day for three months-20 years. Clinical features included confusion, ataxia, and often myoclonus. Median concentrations of bismuth were $800 \mu \mathrm{g} / \mathrm{l}$ in serum and $16 \mu \mathrm{g} / 1$ in cerebrospinal fluid. When bismuth was withdrawn, most patients recovered as blood bismuth concentrations fell

Prescription of TDB has increased recently because it produces longer remissions of duodenal ulcer disease than a course of $\mathrm{H}_{2}$ blockers. This may be because TDB suppresses the growth of Helicobacter pylori, ${ }^{5}$ or because bismuth remains in the body for at least 12 weeks after a course of TDB.

Tripotassium dicitrato bismuthate was licenced in the UK in 1971 for the treatment of peptic ulceration. The recommended dose contains $0.432 \mathrm{~g}$ bismuth per day. Treatment is taken for 28 days followed by a further 28 days if necessary. Maintenance is not indicated but a course may be repeated after an interval of one month. It has been generally recommended that treatment should be stopped if plasma bismuth concentrations are above $100 \mu \mathrm{g} / \mathrm{l}$. Nwokolo et al have pointed out, however, that peak plasma concentrations are frequently greater than 100 $\mu \mathrm{g} / \mathrm{l}$ in normal individuals on TDB, and suggest that trough levels should be measured. ${ }^{7}$ Our patient took twice the usual dose for two months and showed failure to concentrate bismuth in the urine in the face of high blood levels. He ingested a total of about $48 \mathrm{~g}$ of bismuth.

Weller recently described a patient who took the recommended dose of TDB, but for a prolonged period of two years, and developed depression and paraesthesia. Symptoms resolved on stopping treatment. ${ }^{8}$ Bismuth levels, however, were not measured.

2-3 Dimercapto-1-propane sulphonic acid (DMPS) has been used effectively to chelate various heavy metals, and is a safe, orally active drug. ${ }^{9}$ Its use has not previously been described in bismuth intoxication. The tenfold increase in urinary clearance of bismuth without side effects leads us to recommend its use in bismuth toxicity.

The use of TDB is increasing at present and this case is a timely reminder that TDB is contraindicated in renal failure.

We would like to thank Miss Famida Nadiadi for typing the manuscript.

1 Delves HT. Biomedical applications of ICP-MS. Chem Br 1988; 24: 1009-12.

2 Morrow AW. Request for reports: Adverse reactions with bismuth subgallate. Med F Austr 1973; 60: 912.

3 Martin-Bouyer G, Foulon B, Guerbois H, Barin C. Aspects epidemiologiques des encephalopathies apres administration de bismuth par voie oral. Therapie $1980 ; 35$ : 307-13.

4 Martin DF, Hollander D, May SJ, Ravenscroft MM, Tweedle DES, Miller JP. Difference in relapse rates of duodenal ulcers after healing with cimetidine or triopotassium dicitrato bismuthate. Lancet 1981; i: 7-10.

5 Marshall BJ, Armstrong JA, Francis GJ, Nokes NT, Wee SH. Antibacterial action of bismuth in relation to Campylobacter pyloridis colonisation and gastritis. Digestion 1987; 37: 8-15.

6 Gavey CJ, Szeto NL, Nwokolo CU, Sercombe J, Pounder RE. Bismuth accumulates in the body during treatment with tripotassium dicitrato bismuthate. Aliment Pharmacol Ther tripotassium dici

7 Nwokolo CU, Gavey CJ, Smith JTL, Pounder RE. The absorption of bismuth from oral doses of tripotassium dicitrato bismuthate. Aliment Pharmacol Ther 1989; 3: 29-39.

8 Weller MP. Neuropsychiatric symptoms following bismuth intoxication. Postgrad Med F 1988; 64: 308-10.

9 Vasken-Aposhian H. DMSA and DMPS-Water soluble antidotes for heavy metal poisoning. Ann Rev Pharmacol Toxicol 1983; 23: 193-215. 